\title{
CONCEPÇÕES DE UM GRUPO DE ALUNOS DO IFPR SOBRE ENSINO E APRENDIZAGEM
}

\author{
CONCEPTIONS OF A GROUP OF IFPR STUDENTS ON TEACHING AND LEARNING \\ CONCEPCIONES DE UM GRUPO DE ESTUDIANTES DE IFPR SOBRE LA ENSEÑANZA Y EL \\ APRENDIZAJE
}

\section{Camila Muniz de Oliveira (iD) 9}

Mestranda em Educação para a

Ciência e Matemática na (UEM)

Professora de Física, Matemática e

Robótica no Colégio Conexão

camila_muniz98@outlook.com

\section{Higor Valentim da Silva}

\section{iD 9}

Graduando em Licenciatura em

Física (UEM)

higor.v67@outlook.com

\section{Néryla Vayne Alves Dias \\ ID 9}

Doutoranda em Educação

(Unesp/Campus de Presidente

Prudente)

Professora Assistente na

Universidade Estadual de Maringá

(UEM)

nerylaalves@yahoo.com.br

\begin{abstract}
Resumo
Neste trabalho, buscamos analisar concepções sobre o processo de ensino e de aprendizagem de um grupo de alunos do ensino médio técnico do IFPR. Consideramos que a vivência oportunizada pela formação escolar é fundamental para a compreensão da relevância dos conhecimentos formais e importância da construção desses saberes na vida do sujeito, de modo que as vivências oportunizadas nos processos formativos influenciam a concepção dos estudantes a respeito da importância da aprendizagem ao longo da vida. A pesquisa, de natureza qualitativa, fez uso do questionário aberto como instrumento de coleta de dados. Nossos resultados indicam que os estudantes que compartilham uma formação ampla e sólida, possuem uma concepção de aprendizagem relacionada não só à aquisição de conhecimentos, mas ao uso desses conhecimentos para a vida e atuação em sociedade, visando mormente ao desenvolvimento da autonomia. Visão que se afasta de uma formação estagnada, destinada apenas à aprovação nas avaliações.
\end{abstract}

Palavras-chave: Ensino; Aprendizagem; Formação Escolar.

Recebido em: 26 de janeiro de 2021.

Aprovado em: 14 de março de 2021.

Como citar esse artigo (ABNT):

OLIVEIRA, Camila Muniz de; SILVA, Higor Valentim da; DIAS, Néryla Vayne Alves. Concepções de um grupo de alunos do IFPR sobre ensino e aprendizagem. Revista Prática Docente, v. 6, n. 1, e019, 2021.

http://doi.org/10.23926/RPD.2021.v6.n1.e019.id997 


\section{Abstract}

In this work we seek to analyze conceptions about the teaching and learning process of a group of students from the technical high school of IFPR. We believe that the experience provided by school education is fundamental for understanding the relevance of formal knowledge and the importance of building this knowledge in the subject's life. Thus the experiences provided in the formative processes influence the students' conception about the importance of lifelong learning. The qualitative research used an open questionnaire as data collection instrument. Our results indicate that students, who share a broad and solid education, have a conception of learning related not only to the acquisition of knowledge, but to the use of that knowledge in life and for acting in society, aiming mainly at the development of autonomy; a vision that departs from a stagnant formation, destined only to pass exams.

Keywords: Teaching; Learning; School Education.

\section{Resumen}

En este trabajo buscamos analizar concepciones sobre el proceso de enseñanza y aprendizaje de un grupo de estudiantes del bachillerato técnico de IFPR. Creemos que la experiencia que brinda la educación escolar es fundamental para comprender la relevancia del conocimiento formal y la importancia de construir este conocimiento en la vida del sujeto. De modo que las experiencias aportadas en los procesos formativos inciden en la concepción de los estudiantes sobre la importancia del aprendizaje permanente. La investigación cualitativa utilizó el cuestionario abierto como instrumento de recolección de datos. Nuestros resultados indican que los estudiantes, que comparten una formación amplia y sólida, tienen una concepción del aprendizaje relacionada no solo con la adquisición de conocimientos, sino con el uso de esos conocimientos para la vida y el actuar en sociedad, apuntando principalmente al desarrollo de la autonomía; una visión que parte de una formación estancada, destinada únicamente a pasar las evaluaciones.

Palabras clave: Enseñanza; Aprendizaje; Educación Escolar. 


\section{INTRODUÇÃO}

Enorme complexidade envolvem os processos de aprendizagem, já que os sujeitos operam o conhecimento de modo diverso. Nesses processos, interfere a história de vida, o meio, a família, a sociedade, a constituição psíquica, as possibilidades de vivências, fatores orgânicos, entre outros, os quais fazem a aprendizagem e a experiência serem singulares para cada sujeito (VENTRE, 2016). Na concepção de Freire (2016), aprender inexiste sem ensinar e vice-versa, pois " [...] foi aprendendo socialmente que, historicamente, mulheres e homens descobriram que era possível ensinar". Depois disso, constataram que era possível e preciso elaborar caminhos, métodos para ensinar (FREIRE, 2016, p. 25-26).

Do ponto de vista do autor, quando é vivida a autenticidade necessária à prática do ensinar e aprender "participamos de uma experiência total, diretiva, política, ideológica, gnosiológica, pedagógica, estética e ética, em que a boniteza deve achar-se de mãos dadas com a decência e com a seriedade" (FREIRE, 2016, p. 26). Essa experiência nunca é permeada de neutralidade, mas de escolhas, mesmo que a escolha seja não as fazer.

Embora as teorias e pesquisas anunciem e discutam a complexidade que envolve os processos de aprendizagem, na escola, em geral, mantemos a homogeneidade das práticas escolares. "Armazenamos" todos juntos. Estudantes com experiências diferentes, com capacidades diferentes, que processam a aprendizagem de maneira diferente. Mantendo uma forma única de ensinar, uma forma única de pensar, uma forma única de avaliar. Essas vivências interferem no modo como o sujeito se relaciona com o conhecimento, sendo motivos que contribuem para a "ineficiência" dos processos escolares, dificultando a construção efetiva dos conhecimentos. Não é novidade dizer que a formação escolar da educação básica, em especial no ensino público, tem ficado aquém de educar o sujeito para atuar em sociedade, para tomar decisões, para exercer a cidadania.

Freire (2016) é enfático ao afirmar que o papel do professor não deve se limitar a transmitir os conteúdos, mas ensinar a pensar certo. Quando o docente assume a postura de passar um conhecimento pronto e acabado, cobrando memorização, se afasta da possibilidade de compreender o mundo, de fazer relações, de questionar, de pensar certo. "Daí a impossibilidade de vir a tornar-se um professor crítico se, mecanicamente memorizador, é muito mais um repetidor cadenciado de frases e de ideias inertes do que um desafiador. [...]. Fala bonito de dialética, mas pensa mecanicistamente. Pensa errado". (FREIRE, 2016, p. 2829). 
Isso porque "Só, na verdade, quem pensa certo, mesmo que, às vezes, pense errado, é quem pode ensinar a pensar certo". E justamente "uma das condições necessárias a pensar certo é não estarmos demasiado certos de nossas certezas". De modo que "que o pensar certo, ao lado sempre da pureza e necessariamente distante do puritanismo, rigorosamente ético e gerador de boniteza me parece inconciliável com a desvergonha da arrogância de quem se acha cheia ou cheio de si mesmo" (FREIRE, 2016, p. 29-30).

Muito está contido nas palavras de Freire. A visão da transitoriedade do conhecimento, já que somos seres históricos no mundo. O respeito pelos saberes dos estudantes, seres igualmente históricos e marcados por suas histórias. E ainda a compreensão de que, "O professor que pensa certo deixa transparecer aos educandos que uma das bonitezas de nossa maneira de estar no mundo e com o mundo, como seres históricos, é a capacidade de, intervindo no mundo, conhecer o mundo" (FREIRE, 2016, p. 30). É precisamente por sermos seres históricos que nosso conhecimento tem historicidade. "Ao ser produzido, o conhecimento novo supera outro que antes foi novo e se fez velho e se "dispõe" a ser ultrapassado por outro "amanhã’”" Por isso, nesse processo, faz-se fundamental apreender o conhecimento já existente, enquanto "estamos abertos e aptos à produção do conhecimento ainda não existente" (FREIRE, 2016, p. 30).

Esse posicionamento evidencia a sensibilidade e o compromisso ético que requer a atividade docente. No entendimento de Freire (2016), não devemos nos furtar de conhecer, de substanciar a capacidade crítica do educando. Que seja um contínuo processo de busca pelo conhecimento, que seja usado para conhecer o mundo. Outros autores, também, buscam compreender como se dá o processo de aprendizagem dos conhecimentos sistematizados, indicando possibilidades para que seja bem-sucedido.

Para Libâneo (2015, p. 8-9), a aprendizagem se define como “[...] uma forma essencial de desenvolvimento psíquico e o caminho lógico para analisar capacidades humanas", que "conduz ao desenvolvimento através da atividade, tendo-se em conta o papel dos fatores externos do desenvolvimento, com destaque especial à incorporação da cultura vista em sua formação histórica, não como cultura dada".

Na visão de Vygotsky, o social influencia de forma significativa a aprendizagem, uma vez que o coletivo promove o desenvolvimento intelectual (CASTORINA, 2002). Para o autor, “A aprendizagem é um momento intrinsecamente necessário e universal para que se 
desenvolvam na criança essas características humanas não naturais, mas formadas historicamente" (VYGOTSKY, 2010, p.115).

Fica evidente a compreensão do sujeito como um ser histórico. E o quanto a educação escolar deve contribuir nesse sentido. Não como um lugar de armazenamento de informações, de reprodução vazia, mas, como um espaço de leitura, releitura, interpretação, questionamento e curiosidade do mundo, dos saberes culturalmente "necessários" serem apreendidos. Essas experiências que deveriam ser mormente propiciadas pela formação escolar.

Partindo desse contexto, neste trabalho, buscamos analisar concepções sobre o processo de ensino e de aprendizagem de um grupo de alunos do IFPR (Instituto Federal do Paraná) dos cursos técnicos de Produção de Moda e de Informática, integrados ao Ensino Médio. Os sujeitos foram escolhidos porque vivenciam uma formação com padrões diferenciados, período integral, corpo docente qualificado, disponibilidade de laboratórios (informática, ciências, etc.) e que se distancia da formação comumente encontrada na educação pública em geral ${ }^{1}$.

Sabemos que o termo concepção é amplo, sendo definido em dois sentidos principais por Seabra e Lima (2016), o primeiro "mais geral, com definiç̧̃es como "sistemas complexos de explicação" e "rede complexa de ideias, conceitos, representações e preconceitos"”. Deste ponto de vista, "as concepções podem informar a maneira como as pessoas percebem, avaliam e agem com relação a um determinado fenômeno". Já o segundo sentido "mais específico, aparece nas definições como a "operação de construção de conceitos"”. Neste viés, "as nossas concepções envolveriam um processo de formação de conceitos. Alguns autores consideram as pesquisas sobre conceitos como uma fonte importante para determinar as características estruturais das concepções" (SEABRA; LIMA, 2016).

Em nossa pesquisa, consideramos o termo concepções como a forma como os sujeitos participantes percebem e avaliam os processos de aprendizagem. Consideramos que compreender essa problemática, na perspectiva dos estudantes, vislumbra possibilidades de organização do conhecimento escolar a partir da seleção ou exposição dos conteúdos, do uso das metodologias de ensino, ou devido às condições de trabalho docente e de objetivos de

\footnotetext{
${ }^{1}$ Não será possível apontar essas diferenças neste trabalho, mas o recorte aqui apresentado fez parte de uma pesquisa maior que buscou confrontar a visão de ensino e aprendizagem de estudantes de ensino médio de uma escola pública, estudantes de uma escola privada, estudantes de uma escola técnica e estudantes dos cursos de licenciaturas em física e em ciências, todos responderam o mesmo questionário (instrumento de coleta de dados). Como parte da pesquisa, ainda foi aplicado um questionário aos professores (dessas mesmas instituições), para compreender a visão destes a respeito das temáticas. As análises dos demais dados ainda não foram publicadas.
} 
formação bem definidos. A intenção foi perceber a sala de aula como um espaço legítimo de construção do conhecimento pelo olhar do aluno. Para tanto, estabelecemos um diálogo por meio de questões que perpassam as concepções sobre os processos do ensinar e do aprender, através de suas vivências. Nosso instrumento de coleta consistiu em questionário aberto, analisados por meio da análise de conteúdo de Bardin (2011).

O recorte apresentado nesse texto faz parte de uma pesquisa maior, desenvolvida por um grupo de Licenciandos em Física na disciplina de Didática, intentando conhecer a visão de aprendizagem de estudantes e professores de diferentes escolas e classes sociais. Nessa pesquisa (maior) utilizamos dois questionários ${ }^{2}$ (um destinado aos professores e outro destinado aos estudantes) intentando compreender as concepções de aprendizagem de diferentes escolas e públicos: professores e estudantes do ensino médio de uma escola privada e de uma escola pública; professores e estudantes de uma escola técnica de nível médio; e professores licenciandos dos cursos de Física e Ciências de uma universidade pública, todas localizadas na região noroeste do Paraná.

\section{FORMAÇÃO ESCOLAR E AS METODOLOGIAS DE ENSINO: UM BREVE PANORAMA}

De modo geral, as pesquisas em ensino têm indicado que não se sustenta mais um ensino fragmentado, pautado em práticas tradicionais, em que o professor detém o conhecimento, fala a maior parte do tempo, e o estudante, passivo, memoriza as informações que serão avaliadas posteriormente. Uma possibilidade de enfrentamento considera contextualizar os conteúdos, situá-los à realidade, explorar o que os alunos sabem sobre o tema, conduzindo o processo para que o conhecimento seja construído de forma significativa. As possibilidades de superação também perpassam as dimensões do entendimento do currículo em uma perspectiva interdisciplinar, integradora, que possibilite mirar o todo, compreender os fenômenos na sua totalidade (LOPES, 1999; FAZENDA, 2010).

Na visão de Nogaro (2005, p. 14), "Para chegarmos a aprendizagem ou a aprender algo precisamos desejar este objeto ou este algo. É preciso uma mobilização do sujeito em direção ao que deseja aprender". Isto é, “quanto maior a afinidade e a intimidade com a aprendizagem

\footnotetext{
${ }^{2}$ As questões feitas aos estudantes foram: 1) O que significa aprender? 2) $O$ ensino acompanha as mudanças sociais? 3) Você aprende quando o conteúdo é trabalhado de que forma? 4) Os conteúdos trabalhados em sala de aula são interessantes? 5) Para você, estudar é prazeroso? ( ) sim ( ) não - justifique. 6) Você considera que todos podem aprender todas as coisas? 7) Quais recursos didáticos os professores mais utilizam? ( ) quadro negro ( ) livro didático ( ) experimentos ( ) simuladores ( ) recursos multimídia ( ) debates ( ) outros 8) Dos recursos anteriormente sinalizados, quais você mais gosta?
} 
maior será o desejo de aprender. Quanto mais sentido o aluno perceber naquilo que aprendeu mais desejará aprender". Podemos considerar que a aprendizagem advém de um encontro do sujeito com o conhecimento, tecido dialogicamente na relação com o outro.

Anastasiou e Alves (2005) chamam a atenção para as escolas que promovem uma atitude passiva do aluno, relegando-se a transmissão dos conhecimentos. Não há como manter nesse processo uma prática que exclui o diálogo, e que a relação aluno-professor-conteúdo seja exclusivamente determinada por ações do professor.

Por outro lado, o planejamento de um curso (ou de uma aula) e a sua "execução" diz muito sobre as concepções de ensino de um professor ou de uma instituição de ensino. Nesse encaminhamento os "não ditos" falam também. Os silêncios, as lacunas, demonstram posicionamentos, concepções. Quando os conteúdos e recursos metodológicos são ministrados a partir de uma prática memorística, corroboramos para uma formação acrítica, fragmentada, que transmite o conhecimento como verdade absoluta. Formação que mantém a ordem da sociedade como está. Sem promover o pensamento, o questionamento, nutrindo, tão somente, a passividade.

Na contramão desse tipo de formação, o conhecimento escolar deve ser compreendido de maneira articulada, integradora, interdisciplinar. Possibilitando ao cidadão uma leitura "real" do mundo. Para Fazenda (2010), o pensamento interdisciplinar reconhece que "nenhuma forma de conhecimento é em si mesma racional. Tenta, pois, o diálogo com outras formas de conhecimento, deixando-se interpenetrar por elas". Admite os saberes de senso comum como relevante nesse processo, “Ampliando através do diálogo $\mathrm{com}^{3}$ o conhecimento científico, tende a uma dimensão maior, [...], ainda que utópica, capaz de permitir o enriquecimento de nossa relação com o outro e com o mundo" (FAZENDA, 2010, p. 173).

Entretanto, quando olhamos para a qualidade do ensino em nosso país, percebemos que permanecemos estagnados, não aproveitando esse espaço de interação para a construção do conhecimento escolar, tampouco para a formação humana, de valores éticos e convivência.

Para Vaillant e Marcelo (2012), o que se passa nos sistemas educacionais reverbera de modo profundo na vida dos indivíduos e nas gerações futuras. Embora se tenha essa compreensão nas pesquisas, as ações das políticas educativas e de formação acabam por tratar apenas soluções pontuais, imediatas, ou de descobrir modos mais eficientes "para manter a prática estabelecida, em lugar de pensar a longo prazo. Os processos de mudança social e

\footnotetext{
${ }^{3}$ Grifos da autora.
} 
educativa transformarão [...] ainda mais o trabalho dos professores, sua formação e também a valorização que a sociedade faz de seu trabalho" (VAILLANT; MARCELO, 2012, p. 15). No campo educacional, temos problemas que sequer conseguimos assimilar.

Nesse cenário, adentra também as definições impostas pelo currículo, muitas vezes embasados em documentos elaborados por países desenvolvidos. Mozena e Ostermann (2016, p. 238) pontuam que iniciativas deste caráter, seguindo recomendações da $\mathrm{OCDE}^{4}$, "primam pelo desenvolvimento de competências e na avaliação destas como aferimento de qualidade. Por que um currículo de países distantes, com contextos econômicos, sociais e históricos tão diversos do nosso podem influenciar nossas escolhas?".

Não podemos perder de vista que são muitos os fatores que contribuem para a precarização da atividade docente e do insucesso da escola. Aqui nos atentamos para a sala de aula, para compreender de modo mais profundo a relação de aprendizagem do ponto de vista do estudante. Mas não podemos fechar-nos em uma torre de marfim. São diversos os problemas que tencionam a escola e a sala de aula. Interferências externas, prescrições dos currículos e diretrizes oficiais que, por vezes, não consideram a perspectiva sociocultural, pois "as mudanças que ocorrem na forma de ensino [...] volta-se a atenção para as transformações da sociedade e a necessidade de modificar as tradicionais formas de ensinar" (BRIGHENTI; BIAVATTI; SOUZA, 2015, p. 283).

Conforme Mozena e Ostermann (2016, p. 329), há um viés de terceirização da educação. "Terceirizar significa avaliar a qualidade da educação pelos resultados das avaliações, controlar o professor, dar menos tempo para o diálogo e interdisciplinaridade na sala de aula, treinar rapidamente os professores ao invés de uma ampla e continuada formação". Iniciativa que visa reduzir custos e desburocratizar o sistema, e "está na contramão de políticas de formação integradas à estruturação da carreira docente, à política salarial que assegure dignidade ao professor e à garantia de condições adequadas de trabalho" (MOZENA; OSTERMANN, 2016, p. 329).

É interessante destacar que não é simples construir uma visão crítica a respeito da escola, reconhecendo-a como um instrumento que pode contribuir para a manutenção (ou transformação) da sociedade de classes. Pelo contrário, a dinâmica escolar exaustiva contribui para que essa leitura fique velada para professores, gestores e alunos.

\footnotetext{
${ }^{4}$ Organisation for Economic Co-operation and Development. 
São diversas as forças que interferem na "trajetória" da escola. Faz parte de uma sociedade organizada por sistemas político e econômico, geradores de uma sociedade de classes. Neste contexto, o viés neoliberal opera na manutenção das desigualdades, "reconhecendo" que os sistemas educacionais mitigam uma profunda crise de eficiência, eficácia e produtividade. E justificam a crise com base na expansão acelerada e desordenada da educação escolar, que não resguardou a devida qualidade. Alegam ser a organização e a gestão das escolas, os responsáveis pelo insucesso da instituição na formação do cidadão (GENTILI, 1996).

$\mathrm{Na}$ visão de Lacanallo et al. (2007, p.2), os processos educativos vigentes numa sociedade capitalista são justamente produtos de transformações de ordem econômica, política, científica e tecnológica. Consequentemente, a educação, "enquanto uma expressão e resposta a essas transformações, precisa ser analisada a partir de um movimento histórico, pois muito do que se faz hoje nas escolas tem origem e teorias pedagógicas clássicas, certas vezes desconhecidas pelos próprios educadores".

Ao encontro das palavras do autor, a Base Nacional Comum Curricular (2018) explicita esse contexto de mudanças, defendendo que o novo cenário mundial requer do sujeito "reconhecer-se em seu contexto histórico e cultural, comunicar-se, ser criativo, analíticocrítico, participativo, aberto ao novo, colaborativo, resiliente, produtivo e responsável requer muito mais do que acúmulo de informações" (LACANALLO et al., 2007). Todavia, estar contido na letra do documento não é suficiente. É necessário possibilitar essa formação. É necessário viabilizar, de fato, permitindo que seja desenvolvida na escola pública.

Carvalho e Pérez (2003) defendem o uso de metodologias e recursos na preparação das aulas para instigar a curiosidade do aluno. Contudo, toda atividade complementar deve ser estruturada e organizada de modo que auxilie o educando no caminho para compreensão dos conceitos. Segundo os autores, quatro características que podem nortear as atividades propostas: “1) Identificação das ideias dos alunos; 2) colocar em questão as referidas ideias mediante contra-exemplos; 3) invenção ou introdução de novos conceitos e 4) utilização de novas ideias em diversos contextos.” (CARVALHO; PÉREZ, 2003, p.43).

Destarte, não adianta trazer recursos para a sala de aula sem a organização e definição dos objetivos de ensino, dos objetivos da formação que se quer alcançar, papel que é atribuído ao educador. A escolha do recurso e da metodologia a ser trabalhada depende desse 
planejamento, já que cada tema pode ser abordado por meio de diversos recursos, podendo ser mais bem compreendido por um determinado tipo.

Podemos dizer que as metodologias de ensino têm como objetivo comum relacionar os conceitos com o mundo, ampliar o entendimento e propiciar um papel ativo do estudante. Diesel, Baldez e Martins (2017) evidenciam que o uso de diversas metodologias pode oportunizar o desenvolvimento de múltiplas habilidades, bem como mobilizar os alunos para a busca do conhecimento. "Na concepção de Vygotsky a interação social é fundamental para o desenvolvimento cognitivo do indivíduo, por provocar constantemente novas aprendizagens a partir de soluções de problemas sob a orientação [...] de crianças ou adultos mais experientes" (DIESEL; BALDEZ; MARTINS, 2017, p. 281).

Apesar de discutirmos a importância das metodologias no processo de ensino e da aprendizagem, reconhecemos que, na prática, as condições de trabalho sufocam possibilidades "inovadoras", tendo em vista que o tempo empregado para preparo e ministração das aulas com o uso de recursos é maior, requerendo planejamento cuidadoso do andamento dos conteúdos. $\mathrm{E}$ os professores, em geral, não dispõem de tempo para refletir no e sobre seu trabalho. Por isso, embora sejam extremamente relevantes às pesquisas sobre a sala de aula e a relação professoraluno-conhecimento, devemos continuar lutando por melhores condições de trabalho e por políticas públicas que defendam (e sejam colocadas em práticas) uma educação pública de qualidade.

\section{ENCAMINHAMENTOS DA PESQUISA}

Partindo deste respaldo teórico objetivamos analisar concepções de um grupo de alunos do ensino médio técnico sobre o processo de ensino e de aprendizagem. Nossos sujeitos foram 17 alunos do IFPR de um campus localizado no noroeste do Paraná; o grupo foi composto por estudantes do curso Técnico em Produção de Moda e Técnico em Informática, com faixa etária entre 17 e 19 anos.

A escolha do grupo se deu com a intenção de dar voz aos alunos sobre questões que permeiam a relação do aprender. Além disso, consideramos que a instituição escolar do grupo apresenta algumas especificidades como ensino integral, viés tecnológico e formação profissional, bem como vivência de formação com uso de laboratórios, bibliotecas, professores com formação qualificada e até mesmo a dedicação exclusiva. Consideramos que a experiência oportunizada por esse tipo de formação tem influências sobre as concepções de ensino e aprendizagem dos estudantes. 
De origem qualitativa, nossa pesquisa não se ateve a uma representação quantitativa para análise dos dados. Como toda pesquisa dessa natureza, envolveu "[...] a obtenção de dados descritivos sobre pessoas, lugares e processos interativos pelo contato direto do pesquisador com a situação estudada, procurando compreender os fenômenos segundo a perspectiva dos sujeitos, ou seja, dos participantes da situação em estudo" (GODOY, 1995, p.58).

Nossos dados foram obtidos por meio de questionário aberto, composto por oito perguntas. Considerando a limitação de páginas deste trabalho, apresentamos aqui a análise de três questões: 'O que significa aprender?', 'Você considera que todos podem aprender todas as coisas?' e 'Dos recursos utilizados (quadro negro, livro didático, experimentos, simuladores, recursos de multimídia, debates, outros) quais você mais gosta?'. O questionário foi aplicado presencialmente pelos autores deste trabalho. A organização e análise de dados encaminharamse a partir da elaboração de categorias, baseadas na análise de conteúdo de Bardin (2011).

\section{Resultados E Discussões}

Organizamos a análise do material de acordo com às questões. O Quadro 1 apresenta o conjunto de categorias elaborado a partir das respostas dadas a questão: 'Para você o que significa aprender?'. Diante das dezessete respostas dos alunos, elaboramos três categorias que evidenciaram concepções sobre o significado de aprender.

Quadro 1 - Análise da questão 'Para você o que significa aprender?'

\begin{tabular}{|c|c|}
\hline Categorias & Respostas dos alunos 5 \\
\hline $\begin{array}{c}\text { Adquirir } \\
\text { conhecimento }\end{array}$ & $\begin{array}{l}\text { [A2]: O ato de aprender corresponde a ação de adquirir um novo conhecimento sobre } \\
\text { um determinado assunto, seja com o auxilio de outros agentes (professor, tutor) ou } \\
\text { individualmente pela pesquisa. } \\
\text { [A4]: Aprender significa você saber sobre um determinado assunto e conseguir resolver } \\
\text { exercícios propostos. } \\
\text { [A11]: Obter conhecimento sobre determinado assunto. } \\
\text { [A12]: Significa saber algo, conseguir compreensão do que é ensinado. } \\
\text { [A14]: Absorver e entender um conteúdo, não decorá-lo. } \\
\text { [A15]: A compreensão de algo novo. }\end{array}$ \\
\hline $\begin{array}{c}\text { Construir a } \\
\text { autonomia }\end{array}$ & $\begin{array}{l}\text { [A1]: Aprender significa você ter interesse em buscar coisas novas, novos } \\
\text { conhecimentos, se dedicar naquilo que é proposto para poder tirar boas coisas daquilo. } \\
\text { [A3]: Conhecer e aprimorar conceitos, cultura, história, etc. } \\
\text { [A5]: Significa conseguir absorver que é passado para nós, seja pelos professores, ou } \\
\text { qualquer pessoa. Você aprende sozinho também, com pesquisas etc. Quando você } \\
\text { absorve o conteúdo e consegue fazer ligações com ele fora da escola ou de casa, você } \\
\text { aprendeu. Aprender vai muito além de decorar alguma coisa. } \\
\text { [A6]: A capacidade de receber um conteúdo, lendo ou ouvindo uma explicação e poder } \\
\text { utilizar do mesmo quando necessário ou oportuno. } \\
\text { [A7]: Adquirir conhecimento para que possa viver bem. Principalmente de maneira } \\
\text { social. }\end{array}$ \\
\hline
\end{tabular}

${ }^{5}$ Existem pequenos erros de grafias nas transcrições porque foram mantidas as transcrições na íntegra das respostas dadas pelos sujeitos participantes. 


\begin{tabular}{|c|l|}
\hline & [A8]: Ter o conhecimento de algo do qual não se tinha antes, desenvolver a capacidade \\
de solucionar problemas. \\
[A9]: Aprender sempre está ligado a novos conhecimentos, de forma que aprender \\
significa descobrir como utilizar/dominar conhecimentos, por exemplo, aprender a \\
escrever significa descobrir como utilizar e a dominar a escrita assim como aprender \\
dançar, a falar, a andar ou qualquer outras coisas seja ela intelectual ou não. \\
[A10]: É desenvolver conhecimentos, técnicas, habilidades, etc. O aprendizado é \\
fundamental para todas as funções humanas, desde a sobrevivência até o raciocínio \\
lógico, crítico, ético e moral. \\
[A16]: Tomar conhecimento e compreender sobre vários conteúdos e situações no dia \\
a dia. \\
[A17]: A capacidade de absorver informações e captar seu sentido, sem o qual, a \\
informação seria apenas um emaranhado de dados e fatos.
\end{tabular}

Fonte: Pesquisa realizada pelos autores.

Na primeira categoria, denominada 'Adquirir conhecimento', elencamos as respostas de seis sujeitos que relacionaram a aprendizagem à capacidade de aprender um conhecimento novo, um novo saber, que poderia ser mediado por um professor, ou alguém mais experiente, ou ainda adquirido por meio de pesquisas individuais. Percebemos indícios que compreendem o aprender como algo que é do sujeito, como pode ser visto na resposta de A4 " [...] você saber sobre [...]" e A11 "obter conhecimento sobre [...]", negando a possibilidade de aprendizagem ligada à mera memorização. Notamos ainda a concepção de aprendizagem vinculada a uma ação sobre o objeto do conhecimento, como na resposta de A2 "O ato de aprender corresponde a ação de adquirir um novo conhecimento [...]”, ocorrência fundamental para que haja aprendizagem.

Percebemos que, para esse grupo de alunos, aprendizagem se relaciona à aquisição do conhecimento. Os termos compreender, saber, ação sobre objeto do conhecimento, evidenciam uma concepção de construção do conhecimento que se distancia da posição de mera reprodução. Na visão de Vygotsky, o sujeito social não é unicamente ativo, mas, sobretudo, interativo. A aprendizagem se constitui na internacionalização progressiva dos instrumentos mediadores: os processos psicológicos vão do domínio externo para o interno, das interações para as ações internas (psicológicas). Essa internacionalização pode ser entendida como transformação, já que o movimento (externo para o interno) inclui uma reorganização individual, que se opõem à transmissão automática da cultura (CASTORINA et al., 2002).

A segunda categoria, nomeada 'Construir a Autonomia', está composta pela resposta de 10 estudantes. Percebemos aqui uma concepção mais ampla que a anterior, relacionada ao desenvolvimento da autonomia do sujeito. O aprender seria fundamental para tornar o sujeito autônomo, capaz de resolver problemas utilizando os conhecimentos apreendidos, 
desenvolvendo o aprender a aprender, independente dos conteúdos a serem tratados. Apresentam uma visão de aquisição de conhecimento para a vida, aplicada às ações cotidianas, relacionada a outros conhecimentos, que seja estabelecida para ampliar seus saberes. Um novo elemento, embora às vezes implícito, comparece: o desejo de aprender do estudante, parte de sua responsabilidade no processo de aprendizagem.

De certo modo, fomos surpreendidos pelas respostas dos estudantes, principalmente pelo nível de criticidade e amplitude da concepção da aprendizagem. Como defendido por Freire (2016), um processo de aprendizagem que desenvolva a autonomia do sujeito, possibilite a leitura do mundo e o pensar certo seria o ideal a ser perseguido em um processo de educação formal. Não podemos perder de vista, que, quando temos estudantes que pensam que o aprender está relacionado a essas possibilidades, a exigência das ações do corpo docente também aumenta. Exigência de formação, espaços reais de discussão, de possibilidades de resolução de problemas, enfim, sair de uma postura passiva, para uma postura interativa; ver o conhecimento como em processo de desenvolvimento, transitório, em um viés interdisciplinar (CASTORINA et al., 2002; FREIRE, 2016; FAZENDA, 2010).

Outro fator considerado fundamental é a compreensão da responsabilidade do estudante como peça chave nesse processo, o interesse e a interação são indispensáveis para que ocorra a aprendizagem. Na visão de Charlot (2013), para que ocorra mobilização do saber é imprescindível que o estudante deseje participar do processo de ensino e de aprendizagem. Para Ventre (2016), "Aprender significa você ter interesse em buscar coisas novas, novos conhecimentos, se dedicar naquilo que é proposto para poder tirar boas coisas daquilo". Já Nogaro (2005) ressalta que a aprendizagem se torna eficaz a partir do momento em que o indivíduo deseja o objeto do conhecimento. Afinal, cada sujeito está no mundo como um sujeito histórico.

A terceira categoria, denominada 'Não respondeu' contém a resposta de um único estudante, que justificando não ser bom em tratar de conceitos não respondeu a questão, não sendo possível analisar qual seria a sua concepção sobre o aprender.

Apesar de os alunos, de modo geral, não apresentarem em suas respostas como seriam os espaços para desenvolver essa aprendizagem (até porque isso extrapola a questão feita e até mesmo um espaço físico), percebemos que ele se daria em uma dinâmica muito distinta da comumente estabelecida em sala de aula, uma vez que não conseguimos, de fato, uma aprendizagem efetiva e autônoma por meio de ações que tratem o conhecimento de modo 
fragmentado, de ações que coloquem o professor no centro do processo. Isso leva o estudante a uma posição de reprodutor do que leu no livro didático ou do que escutou do professor (CARVALHO; PEREZ, 2003; MOREIRA, 2017; FAZENDA 2010).

$\mathrm{Na}$ sequência apresentamos a análise da questão "Você considera que todos podem aprender todas as coisas?'. Novamente, as respostas foram organizadas em categorias, elencadas no Quadro 2.

Quadro 2 - Categorias da questão 'Você considera que todos podem aprender todas as coisas?'

\begin{tabular}{|c|c|}
\hline ias & Respostas dos alunos \\
\hline $\begin{array}{l}\text { Sim, } \\
\text { relacionando } \\
\text { à capacidade } \\
\text { de aprender }\end{array}$ & $\begin{array}{l}\text { [A3]: Todos têm a capacidade, porem nem todos aprendem da mesma maneira. } \\
\text { [A5]: Sim, mas cada um a sua maneira, mesmo que haja inúmeras dificuldades. } \\
\text { [A7]: Desconsiderando alguns tipos específicos de deficientes que por conta da } \\
\text { deficiência são impossibilitados, sim, mas com graus diferentes de dificuldade. } \\
\text { [A8]: Sim, independente da dificuldade, a capacidade de raciocínio pode ser exercitada } \\
\text { por todos. } \\
\text { [A9]: De certa forma sim, acredito que cada um tem suas aptidões e gostos por áreas, } \\
\text { temas e atividades especifico, porém, existe a possibilidade de aprender de tudo mesmo } \\
\text { que não profundamente como um especialista. } \\
\text { [A10]: Sim, porem algumas podem ter maior facilidade de aprender algo do que outros } \\
\text { acredito que por questões sociais e até mesmo biológicas. } \\
\text { [A14]: Sim, mas depende de como é ensinado a cada um (digo isso incluindo as } \\
\text { pessoas que tem problemas mentais que os impedem). } \\
\text { [A15]: Sim, todas as pessoas podem aprender as coisas que elas quiserem, entretanto } \\
\text { muitas vezes uma força maior de outras pessoas, como o governo não permite. } \\
\text { [A16]: Aprender creio que sim, uns talvez com mais facilidade, outros com menor, } \\
\text { porém acho possível. } \\
\text { [A17]: Sim, ainda que sejamos aptos a determinadas áreas, o gosto está muito ligado a } \\
\text { sensação de dificuldade, forças externas podem mudar o cenário de insatisfação. }\end{array}$ \\
\hline $\begin{array}{r}\text { relac } \\
\text { à nec } \\
\text { de } \mathrm{a}\end{array}$ & mundo mais ampla e fundamentada. \\
\hline $\begin{array}{l}\text { Não, devido à } \\
\text { dificuldade de } \\
\text { aprender. }\end{array}$ & $\begin{array}{l}\text { [A2]: Não, pois há certos conteúdos que mesmo se esforçando para aprender, esta } \\
\text { pessoa não conseguirá compreender e acho que isto se deve devido as aptidões da } \\
\text { mesma } \\
\text { [A11]: Não com certeza não. Cada aluno tem sua individualidade e simplesmente não } \\
\text { que não goste, mas não consegue realizar alguma matéria e vai sempre preferir sua } \\
\text { afinidade. }\end{array}$ \\
\hline $\begin{array}{l}\text { Não, pela } \\
\text { limitação do } \\
\text { ser humano de } \\
\text { aprender } \\
\text { todas as } \\
\text { coisas. }\end{array}$ & $\begin{array}{l}\text { [A4]: No limite do possível, não. } \\
\text { [A6]: Não, nem todo mundo tem a oportunidade de aprender e quem tem nunca vai } \\
\text { saber tudo, há sempre coisas novas. } \\
\text { [A12]: Não considero que todos podem aprender todas as coisas, porque por mais } \\
\text { tempo que a pessoa entender, existe muita coisa da vida passada, presente e que esta } \\
\text { sempre se atualizando. Então é impossível saber todas as coisas. Fora que uns tem mais } \\
\text { facilidade em aprender do que outros. } \\
\text { [A13]: Não! Cada um de nós absorve as coisas de maneira diferente uns mais outros } \\
\text { menos, mas creio que nunca iremos aprender TUDO. }\end{array}$ \\
\hline
\end{tabular}

Fonte: Pesquisa realizada pelos autores.

Essa questão foi proposta com o intuito de perceber se os estudantes conseguiam perceber a singularidade do ser humano, a sua pequenez como sujeito histórico. Isso porque um 
sujeito nunca faz nada sozinho, mas constrói e se constrói na relação com o outro; e possui sempre seu campo de interesse, de habilidades. Notamos que as respostas dos estudantes sobre a possibilidade de aprender todas as coisas perpassaram quatro categorias.

$\mathrm{Na}$ primeira categoria, nomeada 'Sim, relacionando à capacidade de aprender', elencamos as respostas dos alunos que consideram que podemos aprender todas as coisas. Justificando a partir da capacidade humana de aprender, 9 alunos responderam nesta direção (A3, A5, A7, A8, A9, A10, A14, A15, A17). Esses indícios podem ser evidenciados nas respostas dos alunos A5 - Sim, mas cada um a sua maneira, mesmo que haja inúmeras dificuldades, e A8 - Sim, independente da dificuldade, a capacidade de raciocínio pode ser exercitada por todos.

Essa questão perpassa por muitos fatores, respondê-la, sem considerar os múltiplos aspectos, pode não ser condizente com a complexidade que a envolve. Quando admitimos que todos podem aprender todas as coisas, devemos no seu bojo garantir que todos tenham as mesmas condições para aprender, o que não é real. Vivemos em uma sociedade de classes, repleta de contradições e desigualdades. Não temos boas escolas, com bons professores, com estudantes bem nutridos de alimento e de afeto em todos os lugares (FREIRE, 2016; MOZENA; OSTERMANN, 2016; VAILLANT. MARCELO, 2012). Como então poderiam todos aprender tudo? Se não temos sequer as mesmas condições (externas)? Esse seria o primeiro ponto.

Um segundo ponto diz respeito à individualidade do sujeito (CASTORINA et al., 2002; MOREIRA, 2017). Tenho as minhas especificidades, habilidades, áreas de interesse. Nunca vou querer aprender sobre tudo. Até porque, o que é tudo? Não temos essa dimensão exata, o conhecimento está em constante desenvolvimento, e compreende inúmeras áreas.

Considerando a resposta dos alunos, percebemos uma visão ingênua, que pode ser justificada por considerarem um tipo de 'preconceito' dizer que todos não podem aprender todas as coisas. Por isso, um número significativo de alunos (9 alunos) respondeu que sim. Entretanto, ao mesmo tempo que pensam na capacidade individual do sujeito, perdem a dimensão do todo. Digo, de todo o conhecimento produzido, e das condições sociais e da história de vida desses indivíduos. Na verdade, essa visão meritocrática, a qual coloca o sujeito como único responsável por seu sucesso e fracasso é propagada pelo sistema neoliberal, afinal só não consegue aquele que não tenta o suficiente. No entendimento de Gentili (1996, p. 7), “ $O$ neoliberalismo privatiza tudo, inclusive também o êxito e o fracasso social ${ }^{6}$. Ambos passam a

\footnotetext{
6. Grifos do autor.
} 
ser considerados variáveis dependentes de um conjunto de opções individuais através das quais as pessoas jogam dia a dia seu destino, como num jogo de baccarat". Declara ainda que, se grande parte dos indivíduos "é responsável por um destino não muito gratificante é porque não souberam reconhecer as vantagens que oferecem o mérito e o esforço individuais através dos quais se triunfa na vida. É preciso competir, e uma sociedade moderna é aquela na qual só os melhores triunfam" (GENTILI, 1996, p.7).

Visão que consideramos mistificada e perversa, já que a organização do sistema educacional, das políticas públicas e dos sistemas de avaliação (do mercado de trabalho, etc.), parece compactuar com a manutenção das desigualdades, culpabilizando os professores e os alunos pelos insucessos. "Dito de maneira simples: a escola funciona mal porque as pessoas não reconhecem o valor do conhecimento; os professores trabalham pouco e não se atualizam, são preguiçosos; os alunos fingem que estudam quando, na realidade, perdem tempo, etc." (GENTILI, 1996, p.7).

A segunda categoria, denominada 'Sim, relacionando à necessidade de aprender', contém a resposta de um único sujeito (A1), que considera que a capacidade de aprendermos as coisas está relacionada à necessidade desta aprendizagem, o conhecimento possibilita uma visão mais vasta do mundo. Em suas palavras, A1: Sim, para que se tenha uma visão de mundo mais ampla e fundamentada. Conhecimento nunca é demais.

$\mathrm{Na}$ mesma direção das respostas dadas anteriormente, nesta categoria o estudante A1 confirmou que sim, podemos aprender todas as coisas, justificando pela necessidade de aprender. Apesar de ser fundamental aprendermos sobre as coisas, não nos é exigido que saibamos tudo, de tudo. Aqui percebemos também uma visão ingênua. Já que vivemos em sociedade, cada um aprende (e por vezes desenvolve) o conhecimento que tem interesse, aptidão ou que se dispôs a discutir, por vezes grupos discordam, têm opiniões antagônicas; mas na totalidade, vamos ampliando nossos saberes, nossas concepções.

$\mathrm{Na}$ terceira categoria, designada 'Não, pela dificuldade de aprender', constam as respostas de dois sujeitos (A2 e A11), que entendem que não é possível aprender todas as coisas, atestando a partir da relação aos nossos campos de habilidades e dificuldades. Nas palavras de A2: Não, pois há certos conteúdos que mesmo se esforçando para aprender, esta pessoa não conseguirá compreender e acho que isto se deve devido as aptidões da mesma.

Percebemos que estes dois sujeitos apresentam uma visão mais crítica sobre o aprender, admitindo essa impossibilidade a partir das dificuldades individuais dos sujeitos. Novamente 
retomamos aqui que nunca conseguiríamos aprender todo o conhecimento existente, não teríamos interesse em aprender em todas as áreas, e nesse campo as dificuldades e habilidades se justificam, tendo em vista que, para aprender algo, devo me interessar, desejar aprender, mobilizar-me para tal (CHARLOT, 2013; NOGARO, 2015).

Na última categoria, denominada 'Não, pela limitação do ser humano de aprender todas as coisas' elencamos as respostas de quatro sujeitos (A4, A6, A12 e A13) que consideram que não é possível aprender todas as coisas, pela incapacidade do ser humano de apreender todo o conhecimento existente. Isso fica evidente na resposta de A12: Não considero que todos podem aprender todas as coisas, porque por mais tempo que a pessoa entender, existe muita coisa da vida passada, presente e que está sempre se atualizando. Então é impossível saber todas as coisas. Fora que uns tem mais facilidade em aprender do que outros.

Da mesma forma que as respostas elencadas na categoria 3, percebemos aqui maior criticidade nas respostas. Quando afirmam que não podemos aprender todas as coisas pela insuficiência humana de entendimento de tudo que já foi produzido, deixam implícito que compreendem a pequenez do sujeito e, em sua dimensão enquanto sujeito histórico, contribuem, mesmo que de modo pontual ou parcial, para o desenvolvimento da humanidade. Apresentam ainda alguns elementos da individualidade do sujeito nesse processo, que inferimos como um entendimento mais profundo sobre as relações de aprendizagem. Pontos fundamentais quando examinamos a complexidade do processo de aprender, já discutidos por Ventre (2016) e Freire (2013).

Por fim, apresentamos as respostas dadas a uma questão bem específica, que intentou perceber como os recursos metodológicos podem contribuir no processo de aprendizagem desses estudantes. Para tanto foi feita a questão 'Dos recursos utilizados (quadro negro, livro didático, experimentos, simuladores, recursos multimídia, debates, outros) quais você mais gosta?'. A organização analítica segue no Quadro 3.

Quadro 3 - Categorias da questão 'Dos recursos utilizados quais você mais gosta?'

\begin{tabular}{|c|c|}
\hline Categoria & Respostas \\
\hline $\begin{array}{c}\text { Recursos } \\
\text { Tecnológicos }\end{array}$ & $\begin{array}{l}\text { A1: Os recursos de multimídia sempre me agradam mais. Mas gosto de todos os recursos } \\
\text { que auxiliam na aprendizagem (cada um com sua utilidade no lugar certo). } \\
\text { A2: Recursos de multimídia e [...]. } \\
\text { A3: [...] e recursos de multimídia. } \\
\text { A5: [...] e simuladores. } \\
\text { A6: [...] e dos slides porque trabalha com as imagens o que acaba deixando mais } \\
\text { interessante. } \\
\text { A7: Recursos de multimídia. } \\
\text { A9: Recursos de multimídia [...]. Pois são geralmente através dos mesmos que acontece a } \\
\text { exemplificação no mundo real dos conteúdos aprendidos. }\end{array}$ \\
\hline
\end{tabular}




\begin{tabular}{|c|c|}
\hline & $\begin{array}{l}\text { A11: [...] e recursos multimídia em que este último ajuda em todas as áreas do saber e } \\
\text { torna a aula fluida e prazerosa. } \\
\text { A12: Recursos de multimídia, pelo fato de serem mais atualizados e serem algo que tenho } \\
\text { maior proximidade no dia a dia. } \\
\text { A13: Gosto dos [...] e dos recursos de multimídia. Por sair do cotidiano e poder falar } \\
\text { também o que pensa e aprender com os outros, que não seja só o professor. E a aula acaba } \\
\text { sendo mais didática também. } \\
\text { A15: O que mais me atrai são os [...] e os recursos multimídia. }\end{array}$ \\
\hline $\begin{array}{r}\text { Recu } \\
\text { "tradic }\end{array}$ & A2: [...] e quadro negro. \\
\hline Experimentos & $\begin{array}{l}\text { A3: Experimentos e }[\ldots] . \\
\text { A5: Experimentos e }[\ldots] . \\
\text { A10: Coisas ligadas a prática como experimentos, [...]. } \\
\text { A16: Gosto de experimentos, }[\ldots] .\end{array}$ \\
\hline $\begin{array}{l}\text { Debates } \\
\text { (método) }\end{array}$ & $\begin{array}{l}\text { A4: Debates. } \\
\text { A6: Gosto e debates e [...]. Os debates ao os meus preferidos, pois é possível ver diferentes } \\
\text { pontos de vista sobre um assunto. } \\
\text { A8: Debates. } \\
\text { A9: [...] e debates. Pois são geralmente através dos mesmos que acontece a exemplificação } \\
\text { no mundo real dos conteúdos aprendidos. } \\
\text { A10: Coisas ligadas a prática como [...], debates, etc. } \\
\text { A11: Debates e [...] } \\
\text { A13: Gosto dos debates e [...]. Por sair do cotidiano e poder falar também o que pensa e } \\
\text { aprender com os outros, que não seja só o professor. E a aula acaba sendo mais didática } \\
\text { também. } \\
\text { A14: Eu gosto muito das rodas de debates, apesar de muitas vezes não opinar na discussão. } \\
\text { E através da discussão você evolui seus pensamentos. } \\
\text { A15: O que mais me atrai são os debates e [...]. } \\
\text { A16: Gosto de [...], debates (mesmo que não falando muito de ouvir as pessoas no debate). } \\
\text { A17: Gosto de todos, principalmente os debates porque demonstram conceitos e opiniões } \\
\text { fundamentadas organizadas para a defesa de um ponto de vista. }\end{array}$ \\
\hline
\end{tabular}

Fonte: Pesquisa realizada pelos autores.

Essa questão citou no seu enunciado alguns recursos mais comumente utilizados, mas os sujeitos poderiam indicar outros também. As respostas foram organizadas em quatro categorias; e como era possível que o estudante colocasse mais de uma resposta, alguns sujeitos compareceram em mais de uma categoria.

A primeira categoria, nomeamos 'Recursos Tecnológicos', esteve entre as duas categorias mais expressivas. Dos dezessete sujeitos, onze afirmaram gostar dos recursos tecnológicos aliados ao processo de ensino e aprendizagem. De certo modo, a opção não demonstra novidade, já que vivemos em um momento de intenso consumo tecnológico. Além disso, a tecnologia pode oportunizar maior dinamicidade nas aulas, com o uso de simuladores, gifs, figuras, esquemas, entre outros, sendo uma forte aliada nesse processo (DIESEL; BALDEZ; MARTINS, 2017). Permite ainda percebermos que, nesta intensa evolução tecnológica (e científica) da sociedade, os recursos de natureza tecnológica no âmbito escolar ganham destaque na opinião dos alunos. A partir das análises, podemos inferir que, parte dos 
estudantes gostam desses recursos por oportunizarem relacionar os conteúdos com o cotidiano, exemplificar, tornar a aula mais fluída e prazerosa, didática; atualizada.

Por outro lado, a maioria das escolas públicas não apresenta estrutura adequada para o uso dos recursos tecnológicos (poucos aparelhos multimídias, internet ruim, escasso tempo para o preparo e seleção de materiais, etc.). Sendo assim, nossos dados evidenciam que a preferência dos alunos pode ser justificada pela realidade desses estudantes, visto que estão inseridos em um colégio de caráter tecnológico e profissional, o qual valoriza os processos de aprendizagem, e aí está incluído o uso de recursos que oportunizam o estudante ser protagonista da sua aprendizagem.

A segunda categoria, nomeada 'Recursos Tradicionais', contempla a resposta de apenas um estudante, A2, que listou quadro negro (mas também afirmou gostar de recursos tecnológicos). Apesar do quadro negro ser considerado, por muitos, um recurso "arcaico" ou tradicional, ele pode sim fazer parte de uma aula dinâmica, interessante, que permita aos estudantes participarem, resolvendo junto ao professor problemas ou atividades. Essa resposta evidencia também o quanto as formas de aprender são diversas, e que um único recurso nunca atingirá todos os estudantes. Mesmo sendo pouco citado, pode ser explorado como um recurso (aliados a outros), desde que dê espaço à discussão e ao entendimento dos conteúdos tratados, e não seja utilizado meramente para reprodução descontextualizada (MOREIRA, 2017).

A terceira categoria foi denominada 'Experimentação'. Quatro estudantes declaram gostar da atividade experimental no processo de aprendizagem (mais ligada às disciplinas de cunho científico), aparentando justificar o uso do recurso principalmente por oportunizar a manipulação, a prática. Embora não tenha sido uma categoria tão expressiva, demonstra que uma postura ativa, a qual oportuniza ao estudante essa relação do conteúdo com o processo de pesquisa, de desenvolvimento científico, é benquista por alguns estudantes. E a experimentação, quando utilizada para a construção do conhecimento (não como uma receita de bolo), é um recurso potencial para a aprendizagem das áreas científicas ${ }^{7}$.

A quarta categoria, nomeada 'Debate - método', também foi bastante expressiva. Onze estudantes afirmaram ser o debate um recurso produtivo no processo de aprendizagem. Mesmo que possa ser aliado a outros recursos, como leituras de textos, quadro negro, slides, entre outros, o debate oportuniza a confrontação de pontos de vista, a discussão de diversos temas,

\footnotetext{
${ }^{7}$ Mesmo sendo um curso técnico com ênfase em produção de moda e informática, os estudantes tem disciplinas científicas (por exemplo: física, química e biologia).
} 
podendo ser utilizado em praticamente todas as disciplinas. Esse é um método que (também) coloca o estudante no centro do processo de aprendizagem por requerer amplo conhecimento do assunto a ser debatido, auxiliando na compreensão dos conhecimentos prévios dos estudantes sobre um tema. De modo geral, consideram que esse recurso possibilita conhecer diferentes pontos de vista, relacionar conceitos e opiniões, exemplificar o mundo real, evoluir os pensamentos, enfim, tornar a aula mais didática.

\section{CONSIDERAÇõES FinAIS}

Embora as pesquisas geralmente ouçam os professores sobre os processos de aprendizagem, os estudantes também têm muito a dizer. Afinal, são eles que vivenciam esse processo por longos anos durante o curso da educação formal. E a forma como experienciam esse processo certamente tem implicações na vida e atuação desses sujeitos.

Resgatando a especificidade do grupo, estudantes do IFPR, nossa pesquisa objetivou conhecer as concepções sobre o aprender (implícito, nesse caso, a ação do ensinar) e o papel dos recursos metodológicos. Nossos resultados indicaram que, parte dos estudantes relacionam o aprender com a possibilidade de adquirir conhecimento, de desenvolver a autonomia, isto é, a capacidade de atuar no mundo. Mesmo não sendo unanimidade, a aprendizagem não foi vista pela maioria como estanque, dizendo respeito apenas as atividades desenvolvidas na escola como passar nas provas ou tirar notas, ou conquistar o diploma, mas sim relacionada à possibilidade de emancipação por meio da educação. Consideramos essa visão bastante crítica para estudantes de nível médio. Visão essa que pode ter sido oportunizada ou ampliada pela própria vivência de formação escolar.

Nosso segundo questionamento, sobre a possibilidade de aprender, permitiu conhecermos suas ideias sobre a diversidade de saberes, sobre as formas de aprender e sobre o conhecimento produzido pela humanidade. Percebemos duas vertentes, a primeira representada por alunos que acreditam ser possível que todos aprendam sobre tudo, justificada pela capacidade de aprendizagem e pela necessidade de aprendizagem dos seres humanos; já a segunda vertente que considerou que não é possível que todos aprendam tudo, por nossa limitação humana de aprender e pela enorme quantidade de conhecimento produzido. Consideramos que o primeiro grupo apresenta uma concepção mais ingênua, já que não reconhece a singularidade do sujeito e o constante desenvolvimento do conhecimento. Por sua vez, o segundo grupo apresenta maior criticidade, quando reconhece o homem como um sujeito 
histórico, dentro de um processo histórico, que contribui com o desenvolvimento dos saberes, mas reconhecendo sua limitação espaço-temporal.

O terceiro questionamento relacionou-se aos recursos utilizados no processo de aprendizagem. Os estudantes reconhecem como positivos os recursos que oportunizam um ambiente dinâmico, de diálogo e discussão. Refutando um espaço monótono e passivo.

De modo geral, concluímos com nossas análises que existe grande complexidade no processo de aprendizagem. E não existe um único modo para fazê-lo. É preciso que o professor, como mediador fundamental, estabeleça oportunidades de aquisição real do conhecimento e desenvolvimento da autonomia. Que possibilite que o estudante pense e discuta problemas reais. Que os relacione aos conteúdos. A escolaridade formal necessita formar o cidadão para o mundo, para se posicionar frente às práticas que se fazem "naturalizadas", mas que, pelo contrário, podem ser mudadas, porque pelo homem foram instituídas.

Entretanto, para que isso de fato ocorra, mudanças fundamentais devem ocorrer na escola. Estas geralmente vinculadas às políticas públicas: ampliar o tempo de formação (formação integral); viabilizar laboratórios, biblioteca, espaços de arte; fornecer condições dignas de trabalho ao professor (melhores salários, possibilidade de trabalhar em uma única escola, formação docente permanente); favorecer os projetos interdisciplinares, entre outras. A formação escolar propiciada pelos Institutos Federais mostra-se de elevada qualidade. Seria fundamental que todas as escolas públicas tivessem suas condições (materiais, metodológica, de infraestrutura e pessoal) que, sem dúvida, trariam impactos significativos no processo de formação escolar do cidadão, no trato das relações sociais e no encolhimento das desigualdades. Sabemos que mudanças nessa direção dependem de vontade política, estão atreladas a um posicionamento político que se preocupe com a qualidade da educação e não apenas com seus custos. Mas em nossas pesquisas continuamos denunciando que condições dignas de trabalho ao professor e ao estudante são fundamentais para mudanças na educação. Continuamos firmes na defesa de que a escola pública deve formar o estudante para a vida. Este grupo de estudantes, ainda que em processo de formação, aparenta estar no caminho, pautado em ideais de uma formação mais autônoma e crítica, fundamental às nossas escolas e a todos nossos alunos.

Olhando o contexto escolar dessa perspectiva, intuímos que a relação entre professor e aluno, as formas de ensinar, devem ser distintas, já que as formas de aprender o são. Nem todos aprendem da mesma maneira, com a mesma intensidade. Nem todos têm as mesmas habilidades, tampouco os mesmos referenciais culturais e familiares. A complexidade que 
envolve o processo de ensino e aprendizagem é tamanha, que por vezes esse processo se torna árduo, seja para o professor seja para o aluno (VENTRE, 2016).

Diante disso, o educador tem um papel de extrema importância: ser permanentemente provocador e alimentar o desejo de aprender do aluno. Para tal, ele precisa conhecer e dominar os conceitos e as formas de ensinar. Trabalhar em uma perspectiva investigativa, que possibilite o aluno lidar com o levantamento de hipóteses, com situações problemas que promovam o pensar, o raciocinar e a tomada de decisões, em defesa de um ambiente escolar que promova efetivamente a aprendizagem. Possibilitando um espaço de produção e compreensão dos conhecimentos sistematizados (NOGARO, 2015). Entendemos que esses fatores são fundamentais para constituição de um processo de ensino e aprendizagem que promova o conhecimento. Neste contexto, diferentes enfoques para gerir o processo de ensino e aprendizagem, a organização metodológica, se mostram oportunos. Trazer à sala de aula uma atmosfera de curiosidade, desafio e aprendizagem; extrapolar o uso tradicional do giz e "quadro negro", ir além do uso do livro didático.

Consideramos que a vivência oportunizada pela formação escolar é fundamental para a compreensão da relevância dos conhecimentos formais e da importância da construção desses saberes na vida do próprio sujeito. De modo que as possibilidades vivenciadas nos processos de formação, sem dúvida, influenciam o entendimento dos estudantes a respeito da importância da aprendizagem e atuação ao longo da vida. Ou seja, se estudo em uma escola na qual a aprendizagem é firmada no diálogo, que possibilita discutir, debater, minha visão de formação é ampliada (não é apenas para tirar nota e pegar o diploma), mas é para me preparar para vida. Por outro lado, se estudo em uma escola que a prática do silêncio é a que domina, minha concepção de formação se estreita, e acabo "aceitando" que devo sempre silenciar e obedecer às ordens que estão estabelecidas.

\section{REFERÊNCIAS}

ANASTASIOU, Léa das Graças Camargo; ALVES, Leonir Pessate (org.). Processos de ensinagem na universidade: pressupostos para as estratégias de trabalho em aula. 5 ed. Joinville, SC: UNIVILLE, 2005.

BARDIN, Laurence. Análise de conteúdo. São Paulo: Edições 70, 2011.

BRASIL. Base Nacional Comum Curricular (BNCC): Educação é a Base. Brasília: MEC/Secretaria de Educação Básica, 2018. Disponível em: http://basenacionalcomum.mec.gov.br/images/BNCC_EI_EF_110518_versaofinal_site.pdf. Acesso em 02 de Novembro de 2019. 
BRIGHENTI, Josiane; BIAVATTI, Vania Tanira; SOUZA, Taciana Rodrigues. Metodologias de Ensino - Aprendizagem: uma abordagem sob a percepção dos alunos. Revista GUAL, Florianópolis, v. 8, n. 3, 2015, p. 281-304.

CASTORINA, José Antônio; FERREIRO, Emília; LERNER, Delia; OLIVEIRA, Marta Kohl de. Piaget - Vygotsky: novas contribuições para o debate. 6 ed. - São Paulo: Editora Ática, 2002.

CARVAlHO, Anna Maria de; PÉREZ, Daniel Gil. Formação de Professores de Ciências. 7. ed. v. 26. São Paulo: Cortez, 2003, 120 p.

CHARLOT, Bernard. Da relação com o saber às práticas educativas/Bernard Charlot. 1. Ed. - São Paulo: Cortez. Coleção Docência em formação: saberes pedagógicos/coordenação Selma Garrido Pimenta, 2013.

DIESEL, Aline; BALDEZ, Alda Leila Santos; MARTINS, Silvana Neumann. Os princípios das metodologias ativas de ensino: uma abordagem teórica. Thema, lajeado/RS, v. 14, n. 1, 2017, p. $268-288$.

FAZENDA, Ivani Catarina Arantes. Reflexões metodológicas sobre a tese:

"Interdisciplinaridade - um projeto em parceria". In: Metodologia da pesquisa educacional / Ivani Fazenda (org.). -12. ed. - São Paulo: Cortez, 2010, p. 161-180.

FREIRE, Paulo. Pedagogia da autonomia: saberes necessários à prática educativa. $53^{\mathrm{a}}$ ed Rio de Janeiro: Paz e Terra, 2016.

GENTILI, Pablo. Neoliberalismo e educação: manual do usuário. In: SILVA, Tomaz Tadeu da; GENTILI, Pablo. (Org.). Escola $\boldsymbol{S}$. A.: quem ganha e quem perda no mercado educacional do neoliberalismo. Brasília, DF: CNTE (Confederação Nacional dos Trabalhadores em Educação), 1996, p. 9-49. Texto disponível em:

https://barricadasabremcaminhos.files.wordpress.com/2010/06/neoliberalismo-eeducacao.pdf. Acesso dia 28/03/2019.

GODOY, Arilda Schmidt. Introdução à pesquisa qualitativa e suas possibilidades. Revista de Administração de Empresas. São Paulo, v. 35, n. 2, 1995, p. 57-63.

LACANALLO, Luciana Figueiredo; SILVA, Sandra Salete de Camargo; OLIVEIRA, Diene Eire de Mello Bortotti; GASPARIN, João Luiz; TERUYA, Teresa Kazuto. Métodos de Ensino e de Aprendizagem: uma análise histórica e educacional do trabalho didático. In: Anais da Jornada do Histedbr - O trabalho didático da história da educação. 2007, Campo Grande, disponível em:

https://www.histedbr.fe.unicamp.br/acer_histedbr/jornada/jornada7/01apres.htm. Acesso em 31 de Outubro de 2019.

LIBÂNEO, José Carlos. Formação de professores e Didática para o desenvolvimento Humano. Educação \& Realidade, Porto Alegre, v.40, n. 2, 2015, p. 5-24.

LOPES, Alice Ribeiro Casimiro. Conhecimento escolar: ciência e cotidiano. Rio de Janeiro: EdUERJ, 1999. 
MOZENA, Erica Regina; OSTERMANN, Fernanda. Sobre a Base Nacional Comum Curricular (BNCC) e o Ensino de Física. Caderno Brasileiro de Ensino de Física, v. 33, n. 2, p. 327-33, ago. 2016.

MOREIRA, Marco Antônio. Grandes Desafios para o Ensino da Física na Educação Contemporânea. Revista do professor de Física, Brasília, v. 1, n.1, 2017, p. 1 - 13.

NOGARO, Arnaldo. A escola como espaço de aprendizagem. Revista Filosofazer, XIV, $\mathrm{n}^{\circ}$ $26,2005$.

VAILLANT, Denise; MARCELO, Carlos. Ensinando a ensinar: as quatro etapas de uma aprendizagem. Trad. LOPES, M. S. 1. Ed. Curitiba: Ed. UTFPR, 2012.

VENTRE, Denise Estafor. A Docência diante dos diferentes processos de aprendizagem dos alunos. 135 f. Dissertação (Mestrado em Educação) - Programa de Pós Graduação da Faculdade de Educação, Pontifícia Universidade Católica do Rio Grande do Sul, Porto Alegra, RS, 2016.

VYGOTSKY, Lev Semenovich. Pensamento e Linguagem. São Paulo: Martins Fontes, 1987.

VYGOTSKY, Lev Semenovich. Aprendizagem e desenvolvimento na Idade Escolar. In: Linguagem, desenvolvimento e aprendizagem. Vigostky, L. Luria, A. Leontiev, A.N. 11 a Edição. São Paulo: Ícone, 2010, p. 103-116. 